\title{
De constructie van de informatiesnelweg: bit by bit
}

\author{
Citation for published version (APA):
}

van Hoesel, C. P. M. (2001). De constructie van de informatiesnelweg: bit by bit. STATOR. https://doi.org/10.26481/spe.20010628ch

Document status and date:

Published: 28/06/2001

DOI:

10.26481/spe.20010628ch

Document Version:

Publisher's PDF, also known as Version of record

\section{Please check the document version of this publication:}

- A submitted manuscript is the version of the article upon submission and before peer-review. There can be important differences between the submitted version and the official published version of record.

People interested in the research are advised to contact the author for the final version of the publication, or visit the DOI to the publisher's website.

- The final author version and the galley proof are versions of the publication after peer review.

- The final published version features the final layout of the paper including the volume, issue and page numbers.

Link to publication

\footnotetext{
General rights rights.

- You may freely distribute the URL identifying the publication in the public portal. please follow below link for the End User Agreement:

www.umlib.nl/taverne-license

Take down policy

If you believe that this document breaches copyright please contact us at:

repository@maastrichtuniversity.nl

providing details and we will investigate your claim.
}

Copyright and moral rights for the publications made accessible in the public portal are retained by the authors and/or other copyright owners and it is a condition of accessing publications that users recognise and abide by the legal requirements associated with these

- Users may download and print one copy of any publication from the public portal for the purpose of private study or research.

- You may not further distribute the material or use it for any profit-making activity or commercial gain

If the publication is distributed under the terms of Article $25 \mathrm{fa}$ of the Dutch Copyright Act, indicated by the "Taverne" license above, 


\title{
De constructie van de informatiesnelweg: "bit by bit".
}

\author{
Rede \\ in verkorte vorm uitgesproken bij de aanvaarding van het \\ ambt van bijzonder hoogleraar in de \\ Faculteit der Economische Wetenschappen en Bedrijfskunde \\ aan de Universiteit Maastricht \\ op donderdag 28 juni 2001 \\ door \\ Stan van Hoesel
}


(C) Stan van Hoesel, Maastricht 2001 
It often happens, with regard to new inventions, that one part of the general public finds them useless and another part considers them to be impossible.

When it becomes clear that the possibility and the usefulness can no longer be denied, most agree that the wholle thing was fairly easy to discover and that they knew was significant.

\section{Edelcrantz in zijn Treatise on Telegraphs (1796)}




\section{Mijinheer de Rector Magnificus, dames en heren}

Allereerst wil ik de universiteit van harte feliciteren met haar 25-jarig jubileum. Er is in die tijd veel bereikt. Als voorbeeld zou ik willen aanhalen dat er in het begin, ik was zelf nog student op een andere instelling, bij andere een lacherige houding was ten opzichte van deze universiteit en haar onderwijssysteem wan probleem gestuurd leren. Die houding is wel verdwenen, dankzij het succes van hetzelfde systeem en de internationalisering, die beide nu navolging ondervinden op andere universiteiten. Dalarnaast zie je nu een groot aantal oud-medewerkers op belangrijke posities op landelijk niveat. Ik heb er verder veel vertrouwen in dat dit succes de komende jaren kan worden gecontinueerd.

Verder, wil ik deze bijeenkomst gebruiken om u een overzicht te geven in de ontwikkelingen binnen het meest fundamentele onderdeel van de informatie logistiek: de telecommunicatie. De ontwikkelingen worden in chronologische volgorde gepresenteerd, en omlijst met een aantal belangrijke besliskundige problemen, inclusief een verzameling elegante wiskundige stellingen met en hun toepassing binnen de telecommunicatie. Tenslotte, werpen we een blik op de toekomst van de informatie logistiek en beschrij ven we haar plaats en relatie ten opzichte van andere vakgebieden.

Het begrip teleconmunicatie betekent letterlijk communicatie op afstand. Toch zullen weinigen zich hierbij het vervoer per post voorstellen. We verwachten namelijk dat bij telecommunicatie informatie instantaan wan zender naar ontwanger getransporteerd wordt. Dit gebeurt dan via een medium dat informatie via elektriciteit of elektromagnetische golven overbrengt. Ook hier is het informatie transport echter niet helemaal instantaan. Elektriciteit wordt met $10 \mathrm{~km} / \mathrm{ms}$ door draden gestuurd waardoor het nog altijd 2 seconden duurt om op deze manier informatie naar Australië te versturen. Via elektromagnetische golven gaat het in glas met $200 \mathrm{~km} / \mathrm{ms}$ en in de ether met $300 \mathrm{~km} / \mathrm{ms}$. Dus communicatie met mensen op de maan vindt plaats met een vertraging van ruim 1 seconde. Dat zal in de toekomst overigens alleen maar meer worden. Het blijft toch een beetje zuur voor al die mensen die in 1969 vol bewondering naar de eerste stappen op de maan van Neil Armstrong keken, in de veronderstelling dat de uitzending rechtstreeks was.

\section{Het begin.}

De telegraaf kan beschouwd worden als het eerste instrument waarmee telecommunicatie kon worden bedreven. De eerste operationele versies 
ervan staan op naam van Claude Chappe (Frankrijk, 1763-1828), en Abraham Edelcrantz (Zweden, 1754-1821) die in 1793 respectievelijk 1794 beide een versie van de optische telegraaf in werking stelden. Naast de technische problemen bij de ontwikkeling van de telegraaf had men ook te maken met een probleem dat nog steeds van groot belang is voor de telecommunicatie: het protocol, een verzameling regels warin exact omschreven staat hoe een bericht van A naar B moet gaan. Dit betreft de codering van berichten, synchronisatie en routering (wie zendt wanneer en waar naar toe), en de transmissiesnelheid. Beiden gebruikten voor de codering grote woordenboeken. Beiden waren ook de eersten die een netwerk van verbindingen realiseerde, voornamelijk gebaseerd op lijnen waarvoor financiering verkregen kon worden door externe geldschieters (meestal het leger). Hieronder het netwerk van Frankrijk van rond 1800.

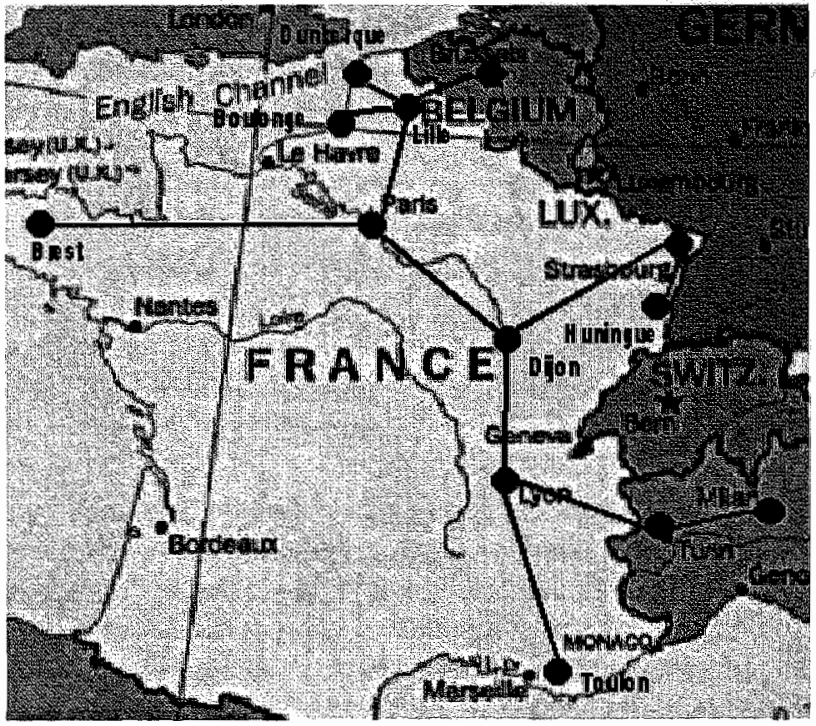

De optische telegraaf heeft een groot aantal nadelen. Bijwoorbeeld dat ze goed zicht vereist. Hij doet daarom toch een beetje primitief aan, vergelijkbaar met de rooksignalen uit de tijd van de indianen.

De elektrische telegraf van Samuel Morse (VS, 1791-1872) uit 1831 had een belangrijk technisch voordeel boven de optische telegraaf, $\mathrm{nl}$. dat niet meer op regelmatige afstand mensen nodig waren om het signaal door te geven. Morse zelf is echter voornamelijk bekend geworden met zijn 
coderingssysteem waarbij de woordenboeken van Chappe en Edelcrantz vervangen werden door een 2-tallig stelsel waarmee letters gerepresenteerd werden. Deze code was bijzonder efficiènt, matar had als nadeel dat lettercombinaties niet uniek waren. Dit in tegenstelling bijvoorbeeld tot de bekende Huffman codering [10], die bijna teven efficiënt is, maar tegelijkertijd bijzonder eenvoudig te ontcijferen, vanwege het feit dat geen enkel symbool de prefix kan zijn van een ander symbool. De Huffman codering is niet alleen elegant, maar tegelijkertijd de meest efficiënte in zijn soort.

De relatief eenvoudige bediening van elektrische telegrafen, samen met voonoemde eigenschappen, waren er debet aan dat al gauw de optische telegrafen uit het straatbeeld verdwenen.

Het duurt nog 45 jaar voordat de volgende grote innovatie zijn intrede doet. De telefoon, uitgevonden door Alexander Graham Bell (1847-1922) en anderen in 1876, maakte het mogelijk om de binaire codering van de telegraaf te vervangen door gewoon stemgeluid. Zoals Bell het zelf, in alle bescheidenheid, zegt:

"This invention's greatest advantage over every other form of electrical apparatus is the fact that it could be used by anyone, as all other telegraphic machines produce signals which require to be translated by experts, and such instruments are therefore extremely limited in their application".

Net als bij de telegraaf, verschenen al vrij snel na de introductie van de telefoon de eerste netwerken van klanten, waar voor het eerst ook (rijke) particulieren deel van witmaakten. Je kunt zeggen dat de "time to market" van het product met twee jaar bijzonder snel was. Alhoewel Bell zelf een netwerk in gedachten had waarin alle klanten met afzonderlijke lijnen met elkaar verbonden waren, een volledig verMAASid netwerk, bleken de eerste telecom bedrijwen meer te zien in geschakelde netwerken, waarin de klanten met een centrale verbonden waren, een STER netwerk.

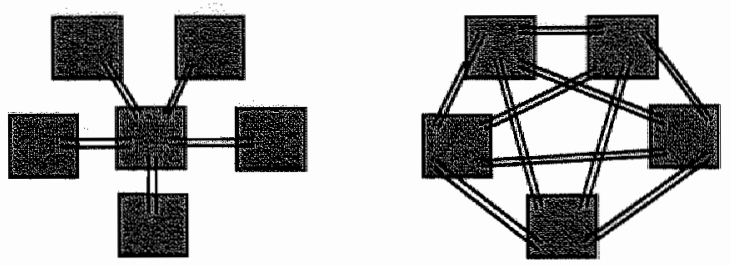


Het voordeel van een STER netwerk ten opzichte van een MAAS, is dat er voor het verbinden van $n$ klanten, maar $n$ verbindingen nodig zijn, en voor een MAAS $\frac{1}{2} n(n-l)$.

\begin{tabular}{|r|r|r|}
\hline$n$ & STER & MAAS \\
\hline 10 & 10 & 45 \\
\hline 100 & 100 & 4950 \\
\hline 1000 & 1000 & 499500 \\
\hline
\end{tabular}

Het nadeel van een STER is dat slechts een klein deel van alle klanten simultaan een gesprek kan voeren. Daarnaast betekent uitval van een verbinding dat de klant geen enkel gesprek meer kan voeren.

Het eerste operationele geschakelde netwerk ontstond in 1.878 in New Haven Connecticut met 21 klanten en én schakelcentrale, ofwel "switch". Via een ingewikkeld schakelmechanisme kon men enkele (niet veel) gesprekken tegelijk laten plaatsvinden. De bediening van de centrale was (deels) handmatig. Binnen korte tijd kwamen er diverse van deze netwerkjes en ontstond de behoefte ze met elkaar te verbinden. Deze verbindingen moesten een zekere mate van betrouwbaarheid en capaciteit leveren en daarom werden hiervoor meer dan de strikt noodzakelijke verbindingen gelegd. Het eerste gelaagde netwerk was een feit. De toplaag was een MAAS en de onderste laag bestond wit STERren.

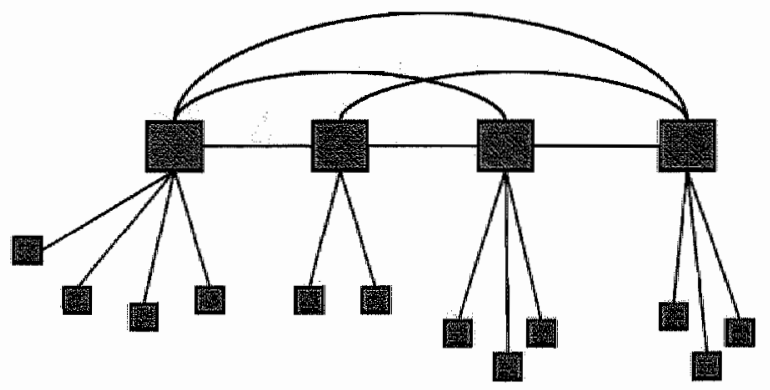

De hierboven geschetste ontwikkelingen brachten, historisch gezien, de klassieke, maar nog steeds actuele, planningsproblemen met zich mee. 
1. Beschikbaarheid van verbindingen, ook wel "Quality of Service" (QoS) genoemd.

Hiermee wordt de kans op succesvolle verbinding bepaald bij aanvraag van een gesprek. Hiervoor werden en worden wachtrij modellen voor aankomst en tijdsduur van gesprekken ontwikkeld. Het telefoonverkeer wordt gemodelleerd met behuip van geheugenloze Poisson processen. Deze processen worden gebruikt om zowel aankomst als tijdsduur van telefoongesprekken te modelleren. Als de gemiddelde vraag naar gesprekken en de gemiddelde tijdsduur bekend is dan geeft de Erlang [4] formule vervolgens de kans op verbinding bij een gegeven aantal mogelijke verbindingen. Deze methodiek vormt een onderdeel van de Stochastische Besliskunde. Ze valt grotendeels buiten het bereik van deze beschouwing.

\section{Netwerk synthese. Hier wordt bepaald wat de structuur of topologie van het netwerk is op de verschillende niveaus.}

De eisen die aan het netwerk gesteld worden op ieder niveau bepalen de structuur van het netwerk op dat niveau. De twee belangrijkste eisen zijn:

1. Korte routes. Hoe groter het aantal verbindingen dat een telefoongesprek moet doorlopen hoe groter de kans op vertraging en storing. Ten slotte wordt capaciteit bij lange routes ook inefficiënt gebruikt, en is deze moeilijker goed te bepalen.

2. Protectie. Hoe overleeft een netwerk storingen in verbindingen en centrales. Deze "overleefbaarheid" wordt direct bepaald door de samenhang van het netwerk: hoeveel verbindingen (of centrales) moet je minstens weghalen opdat het netwerk in twee of meer delen uiteen valt. Tegenwoordig onderscheiden we (nationaal) drie niweaus met ieder hun specifieke eisen ten aanzien van de samenhang. Op het allerlaagste niveau is 1 -samenhang vaak al voldoende, aangezien bij breuk een zeer beperkt deel van de klanten wordt getroffen. Op een iets hoger miveau is 2-samenhang. vakk noodzakelijk om ervoor te zorgen dat er bij één breuk nog verbinding mogelijk is. Op het hoogste niveau is nog grotere samenhang vaak gewenst. De reden hiervoor is de wens naar verbindingen tussen centrales te hebben.

Binnen de grafen theorie modelleert en bestudeert men deze problemen: bijvoorbeeld samenhang vertaalt zich direct in het aantal mogelijke disjuncte routes tussen ieder tweetal centrales (Menger [16]). In de praktijk wordt vaak gekozen voor eenvoudige structuren: 


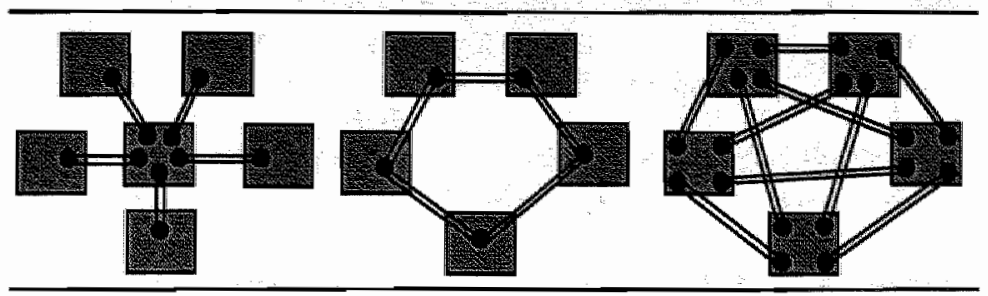

Bron: H. Meeuwissen, KPN Research

Voor een structuur die uit $n$ klanten bestaat geldt:

\begin{tabular}{|l|c|c|c|}
\hline Structur & $\begin{array}{c}\text { Aantal } \\
\text { verbindingen }\end{array}$ & Samenhang & $\begin{array}{c}\text { Kortste } \\
\text { route }\end{array}$ \\
\hline STER & $n$ & 1 & 2 \\
\hline RING & $n$ & 2 & {$\left[\frac{n}{2}\right]$} \\
\hline MAAS & $\frac{1}{2} n(n-l)$ & $n-l$ & 1 \\
\hline
\end{tabular}

Nationaal (backbone), regionaal, plaatselijk

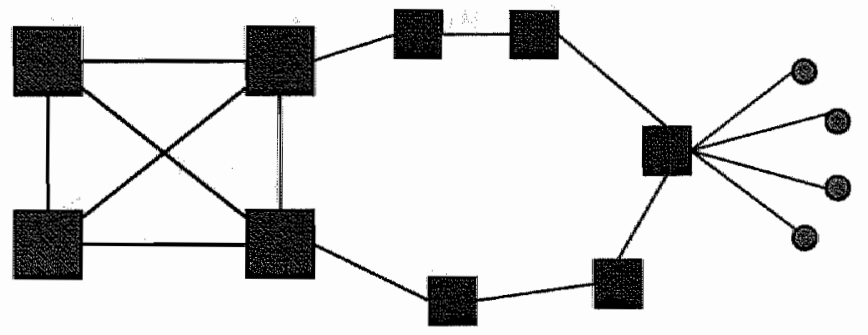

De theorie houdt zich bezig met route lengte bepaling en overleefbaarheid door voor een gegeven verzameling centrales alle mogelijke verbindingen te beschouwen en daaruit een deel te selecteren zodanig dat aan de eisen met betrekking tot route lengte en/of overleefbaarheid gedaan wordt. De kosten voor het uitwoeren van $\mathrm{zO}^{*} \mathrm{n}$ netwerk (het leggen van de verbindingen) worden dan geminimaliseerd. Als voorbeeld: proefschrift van Wynants [24]. 
3. Planning capaciteit (inclusief routering). Indien de topologie van een netwerk vastligt moet nog bepaald worden wia welke weg een gesprek loopt en hoeveel gesprekken er per werbinding tegelijkkertijd plaats kunnen vinden.

Routering is bij de oorspronkelijke telefonie netwerken een vrij triviaal probleem er is maar cén route (de kortste) van zender naar ontwanger in het netwerk. Diarom weten we precies welke telefoongesprekken er over een verbinding lopen. De Poisson processen voor deze telefoongesprekken (vaak op basis van afstand: gesprekken tussen personen op geografisch grotere afstand komen minder vaak voor) leveren goede input voor de benodigde capaciteit om een gegeven minimum service garantie (QOS), zoals kans op verbinding bijv. tenminste $99 \%$, te realiseren. In de huidige netwerken is routering echter een stuk complexer en sterk afhankelijk van de diverse protocollen. Daarmee wordt de capaciteitsplanning ook een stuk ingewikkelder. We komen hier later op terug.

De gebruikte modellen voor capaciteits- en routeringsproblemen komen voornamelijk uit het vakgebied van de Deterministische Beshiskunde.

Een eenwoudig, maar frequent voorkomend capaciteit/routering probleem is het probleem, waarbij gevraagd wordt hoeveel gesprekken we tussen twee gegeven centrales kunnen voeren. Dit probleem kan als een zogenaamd stromingsprobleem gemodelleerd worden.

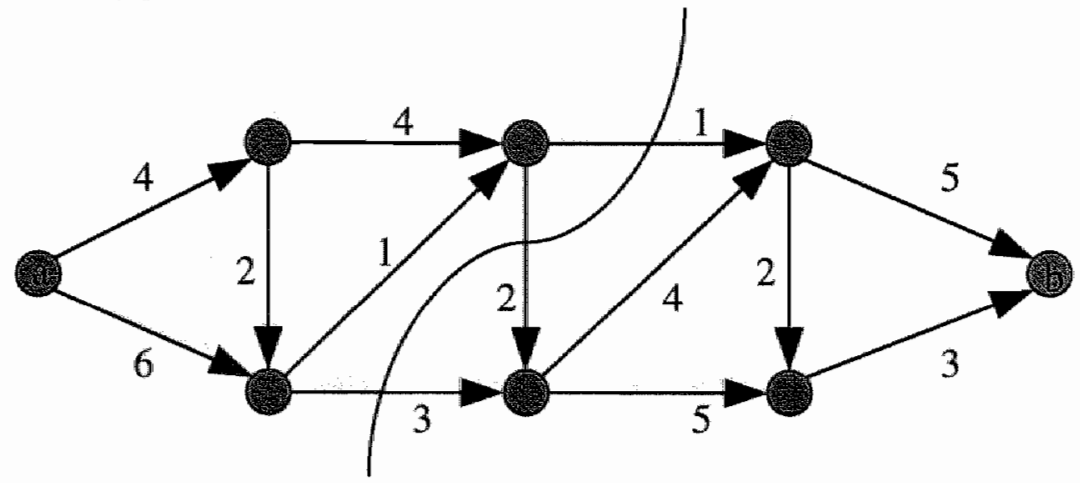

In bovenstaand netwerk wordt gevraagd hoeveel gesprekken er van de linker centrale $a$ naar de rechter centrale $b$ gevoerd kunnen worden rekening houdend met de gegeven capaciteit op de verbindingen. We zien vrij direct dat er éen gesprek bovenlangs en drie gesprekken onderlangs gevoerd 
kunnen worden. Daarnaast kunnen nog twee gesprekken gerouteerd worden. Zes gesprekken is ook het maximum: de gekromde lijn geeft een snede (bottleneck) waarover alle gesprekken van $a$ naar $b$ moeten. De cumulatieve capaciteit van de kanten van deze snede is echter ook zes. Ford en Fulkerson [5] toonden aan dat het geen toeval is dat de kleinste snede dezelfde waarde had als de grootste hoeveelheid gesprekken (stroom) door het netwerk: de maxflow-mincut stelling, een generalisatie van de stelling van Menger.

In Schrijver [19] wordt de vroegst bekende toepassing, van Tolstoil [21], van het stromingsprobleem beschreven. Deze geeft ook al een methode van aampak.

In de beginjaren van het communisme hadden de Russen een (trein)netwerk waarvan ze wilden weten hoeveel ton goederen er per tijdseenheid over vervoerd konden worden van Rusland naar Oost-Europa, gegeven dat ieder baanvak een beperkte (bekende) capaciteit had. De Russen kwamen met een oplossing van 163.000 ton. De Amerikanen, meer geinteresseerd in hoe ze dit vervoer efficiënt konden uitschakelen, zullen geïnteresseerd zijn in de bottleneck van dezelfde waarde.

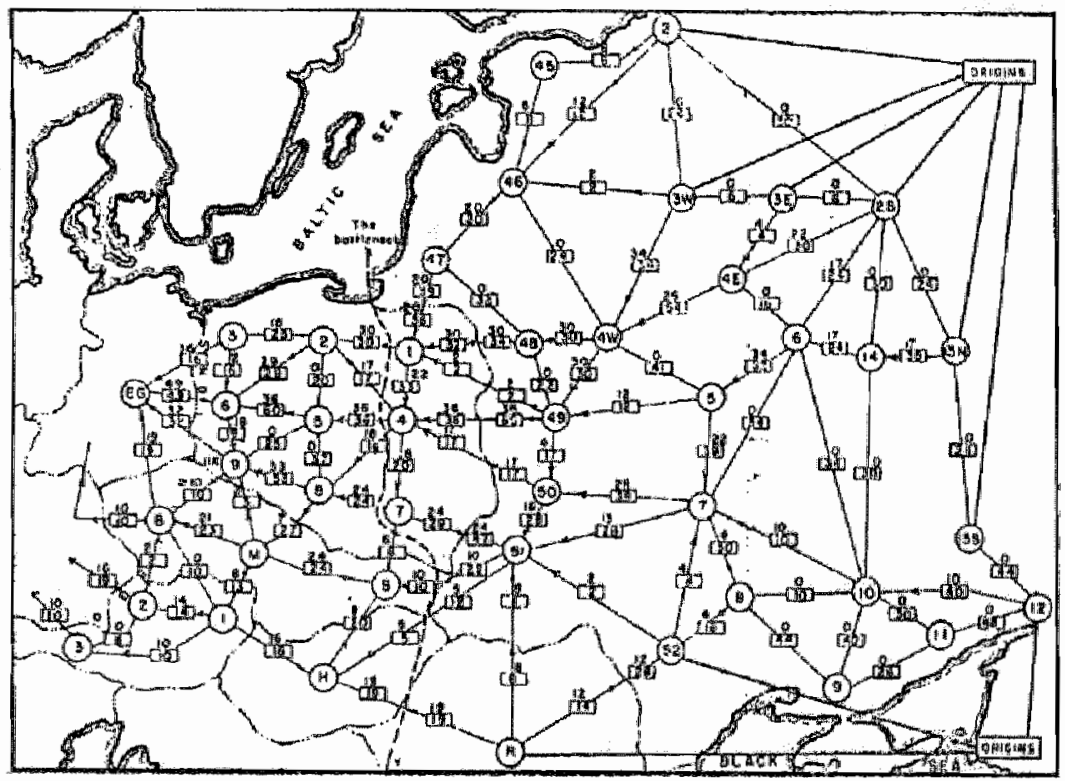


In het algemeen willen meer met een netwerk dan alleen gesprekken tussen twee gegeven centrales. Met andere woorden er is een aantal puntenparen in ons netwerk waartussen we vraag naar verbindingen hebben (meerdere zogenaamde "commodities". Voor dit probleem is in het algemeen niet zo" $\mathrm{n}$ elegante min-max relatie. Voor planaire netwerken, en aanvullende eisen voor de commodities hebben Okamura en Seymour [17] echter wel de maxflow-mincut stelling kunnen aantonen.

Capaciteitsplanning is niet alleen noodzakelijk om aan de standaard vraag naar gesprekken te voldoen, maar er dient ook een zekere hoeveelheid capaciteit gelegd te worden om bij uitval van verbindingen op de overige verbindingen rekening te houden met omgeleidde gesprekken. Daarnaast dient met kortstondige piekvraag rekening gehouden te worden. Deze voorzieningen worden vaak aangebracht op een deel van het netwerk. Neem een MAAS. Gegeven is een verzameling piekvragen. We moeten nu een 1samenhangend netwerk maken dat ieder van de piekvragen afzonderlijk kan opvangen. Dit moet gebeuren door extra capaciteit op een aantal kanten te leggen. Een ster is een envoudige oplossing, die zowel in de praktijk als in theorie (2-approximatie) goed voldoet, maar niet optimaal hoeft te zijn. Zie voorbeeld. Het eerste plaatje geeft de gevraagd capaciteit voor ieder van de paren centrales. Het door ons te ontwerpen netwerk van verbindingen met capaciteit, dient in staat te zijn om ieder van deze capaciteitsvragen te vervullen, maar niet simultaan.
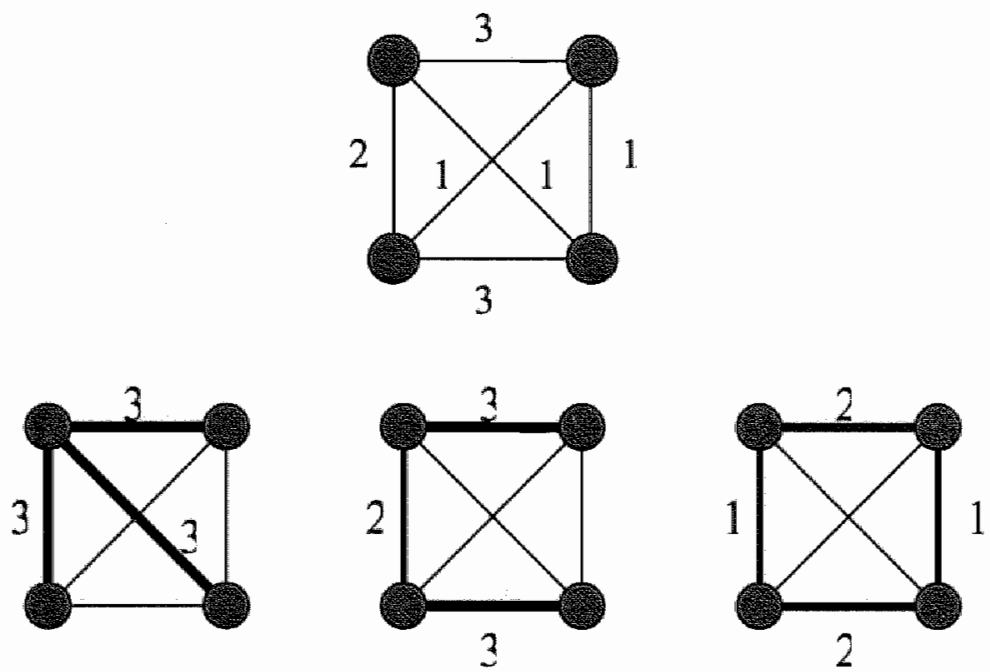
In bovenstaande netwerken zijn drie oplossingen weergegeven door middel van de dikke kanten, met de daarop gelegde capaciteit. In het eerste netwerk is dit een ster. Nu moet tussen ieder tweetal punten een weg zijn met minimum capaciteit minstens de in de bovenste tekening aangegeven waarde voor het betreffende puntenpaar. Het is niet moeilijk te verifieren dat dit kan. Merk op dat in het laatste netwerk meerdere wegen per puntenpaar gebruikt worden. De ster kost in total $9(=3 \times 3)$ eenheden capaciteit. Waar we het centrale punt van de ster ook neerleggen, de twee puntenparen met vraag naar capaciteit van 3 dwingen alle kanten van de ster tot het dragen van 3 eenheden. Indien we ons beperken tot bomen (acyclische 1-samenhangende deelnetwerken; in feite zorgvuldig aan elkaar geplakte sterren), dan bestaat er een elegante oplossing die in bovenstaand voorbeeld maar 8 eenheden kost: een zogenaamde maximum opspannende boom. Indien geen beperkingen aan de structuur van de gekozen verbindingen worden opgelegd kan een verdere capaciteitsreductie optreden. In het voorbeeld naar 6 eenheden. Indien alle piekvragen tegelijk op kunnen treden wordt het probleem interessanter: de zogenaamde Gomory-Hu tree [9] geeft een optimale boom. Fortz en van Hoesel [7] beschrijven het probleem met behulp wan een elegant polyeder. Als ook nog variatie in kosten mogelijk is en/of het netwerk niet vermaasd, dan wordt het probleem echt moeilijk (=leuk). Het probleem heeft verder een leuke toepassing in de biologie, zie [23].

\section{Moderne telecommunicatie.}

De moderne telecommunicatie is ongeveer 20 jaar geleden ontstaan nadat een kleine revolutie had plaatsgevonden, met grote gevolgen: de digitalisering van informatie. De CD speler en de bureau computer zijn twee producten hiervan die snel voor de consument beschikbaar kwamen. De digitalisering is uiteraard ook toegepast op het transport van informatie: telecom netwerken. Allereerst, in de jaren ' 80 waren er de technische ontwikkelingen. Daarna is ook een groot aantal nieuwe gebruikers applicaties grootschalig ingevoerd. Dit bespreken we later.

In de jaren ' 80 werden digitale netwerken vooral ontwikkeld voor telefonie. Een gesprek werd omgezet in een $64 \mathrm{~kb} / \mathrm{s}$ bitstroom. 30 van zulke bitstromen werden gebundeld tot een $2 \mathrm{Mb} / \mathrm{s}$ signaal. Dit basis signaal werd telkens met 3 andere gebundeld in $8-34-155-622 \mathrm{Mb} /$ seconde signalen. Dus telkens cen factor 4 (met een beetje overhead voor het transmissie protocol). De capaciteit van een verbinding hing direct af van de geplaatste apparatuur (multiplexers) aan de uiteinden van een koperdraad. Ze kon dus relatief 
gemakkelijk (zonder graven) uitgebreid worden door betere apparatuur te plaatsen.

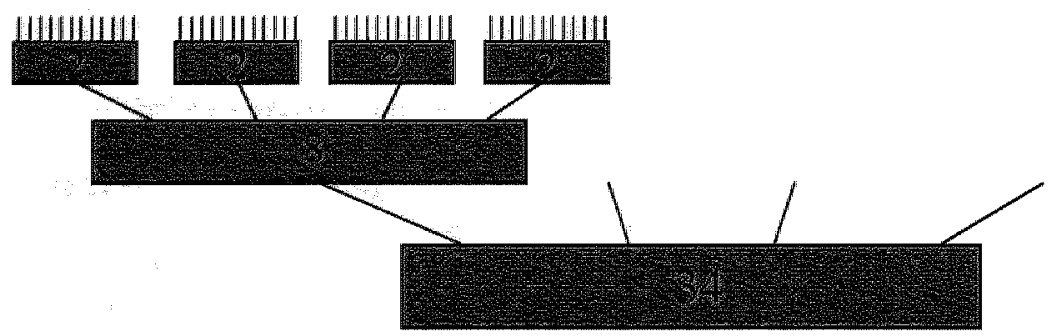

In de jaren ' 90 heeft de grootschalige introductie van een drietal belangrijke ontwikkelingen plaatsgevonden.

1. Optisch signaaltransport in vaste netwerken

2. Draadloos signaaltransport

3. Nieuwe diensten (voor dataverkeer): TCP/IP (internet) en ATM.

\section{Optische netwerken.}

De optische netwerken zijn pas goed tot ontwikkeling gekomen gedurende de laatste vijf jaren. Deze netwerken, bestaande uit glasfiber draden waardoor licht verstuurd wordt, kunnen bits met veel hogere snelheid vervoeren dan de ouderwetse koperdraden dat met behulp van electriciteit kunnen. Waar kopernetwerken tot $622 \mathrm{Mb} / \mathrm{s}$ kunnen verwerken, begint glasfiber vanaf $2.5 \mathrm{~Gb} / \mathrm{s}$. $40 \mathrm{~Gb} / \mathrm{s}$ apparatuur is al beschikbaar en in het laboratorium is al $1 \mathrm{~Tb} / \mathrm{s}$ gehaald. Om een idee te geven hoeveel dat is: 1 seconde data is 5 keer de wereld rond met op iedere millimeter 5 enen of nullen. Daarnaast kan licht op verschillende golflenglen (kleuren) tegelijk door een fiber verstuurd worden. Het zogenaamde WDM (Wave Division Multiplexing). Momenteel worden zo'n 64 kleuren gebruikt, en dit worden er snel meer.

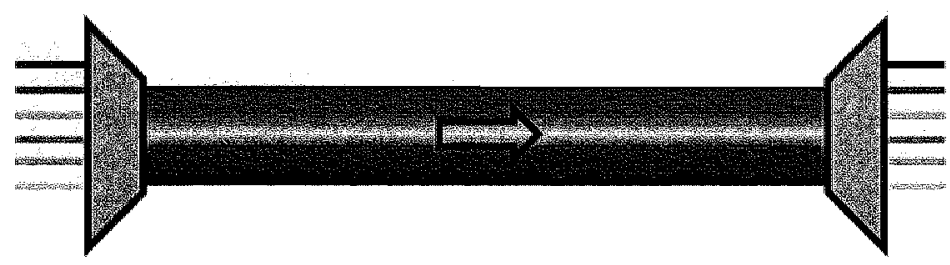


Verhoging van snelheid en aantal kleuren ligt voor de hand en zal iedere 3 jaar naar verwachting een verviervoudiging van capaciteit met zich meebrengen, puur door verbeteringen in de apparatuur van de centrales.

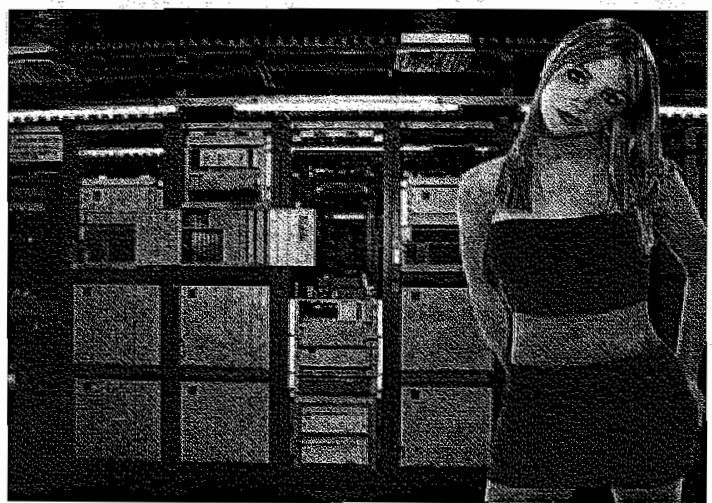

Lucent HFC-2000: Glasfiber Breedband Access Systeem, met monteur. Bron: http://www privateline.com/archive/britney.htm

Deze ontwikkeling staat bekend als de Wet van Moore (oud-CEO INTEL). Moore heeft in de jaren '60 voorspeld dat het aantal elektronische schakelingen op een processor iedere 1,5 à 2 jaar verdubbelt. Tot op heden wordt zijn gelijk bevestigd door het onderstaande plaatje.

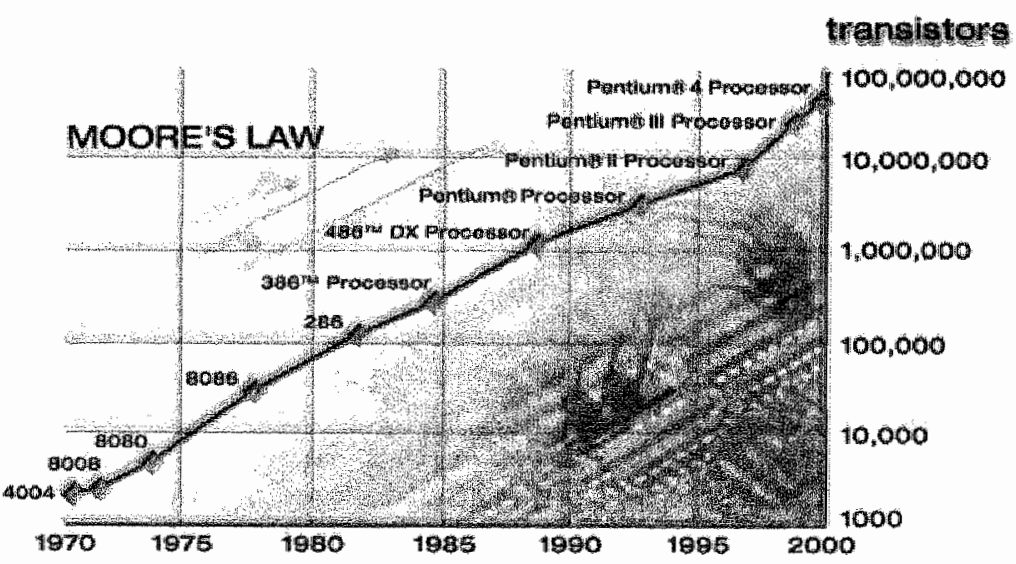

Bron: http:/www.intel.com/research/silicon/mooreslaw.htm 
De topologie van optische netwerken is een beetje vreemd op het eerste gexicht. In plaats van losse werbindingen tussen paren centrales worden ringen gellegd. Met SDH (Synchronous Digital Hierarchy) technologie, een multiplex protocol, legt men vervolgens een vaste capaciteit over een ring die in ér richting gebruikt kan worden. Om te veel vertraging, voornamelijk veroorzaakt door centrales, te voorkomen wordt het aantal centrales beperkt tot maximaal 16 (in de praktijk veel minder). Het eerste probleem is uiteraard gegeven een aantal centrales om hier ringen door te leggen. Dit synthese probleem is in Nederland vrij eenvoudig opgelost. Er is een hoofdnet van 8 centrales met daaromheen subnetten die nog eens 10 centrales meenemen. Het netwerk van hoofdcentrales is erg dik overdekt met ringen, zodanig dat ieder paar hoofdcentrales op minstens éen ring tezamen ligt. In het algemeen zal men het aantal ringen plannen aan de hand van de kosten om ze neer te leggen. Zie Fortz [6].

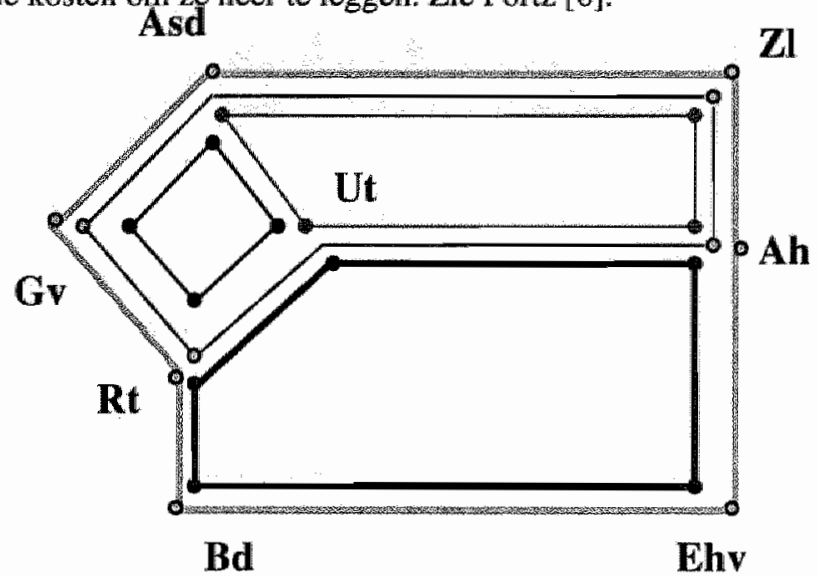

Bron: O. Koning, KPN research

Als de ringen er eenmall liggen dan spelen er weer diverse planningsproblemen. Een verbinding tussen twee centrales wordt gelegd door een kleur te nemen en in ieder van de twee centrales een filter (multiplexer) te plaatsen voor die kleur. In de tussencentrales is verder weinig apparatuur nodig. Daarom is zo'n fysieke ring een, logisch gezien, vermaasd netwerk. Merk op dat bij ringen de protectie goed geregeld is ondat deze 2-samenhangend is. Bij falen van apparatuur in een centrale of op de ring zelf, neemt een tweede ring het verkeer zelfs automatisch over. Het, bij gegeven vraag naar capaciteit (kleuren) tussen de centrales, toekennen van kleuren aan routes op een ring is echter wel aan restricties 
gebonden: als twee routes fysiek overlappen dan kunnen ze niet dezelfde kleur krijgen. Het optimaal toekennen van kleuren is in theorie een (NP-) moeilijk probleem. Als we de ring openknippen wordt het probleem ineens makkelijk (=polynomiaal oplosbaar).

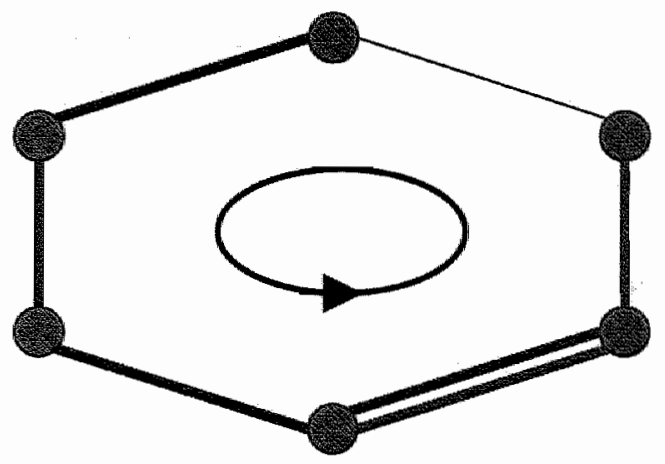

SDH-ringen worden tegenwoordig dubbel uitgevoerd zodat verkeer in twee richtingen mogelijk is. Nog steeds geldt echter dat de hoeveelheid capaciteit op iedere verbindling van de ring hetzelfde moet zijn. Het minimalliseren van deze capaciteit komt neer op het goed kiezen van de draairichting (routeren) van iedere verkeersvraag. Doordat een ring planair is, met ieder punt aan de buitenkant kunnen we hiervoor de resultaten van Okamura en Seymour [17] gebruiken. Zie Schrijver et alii [20], en ook Dell' Amico et alii [3]. Dit is dan ook in theorie een makkelijk probleem.

\section{Draadloze communicatie.}

Mede door de sterke compressie technieken van spraak, werd het mogelijk om via het GSM protocol een meerdere gesprekken te vervoeren over een eenheid capaciteit. De TDMA (Time Division Multiplexing Access) techniek is in staat om 8 gesprekken tegelijk te verzenden (minus eventueel een kanaal gereserveerd voor het beheer van het netwerk) over een frequentieband van $200 \mathrm{kHz}$. Hiervoor zijn de $900 \mathrm{MHz}$ en de $1800 \mathrm{MHz}$ band gereserveerd. 


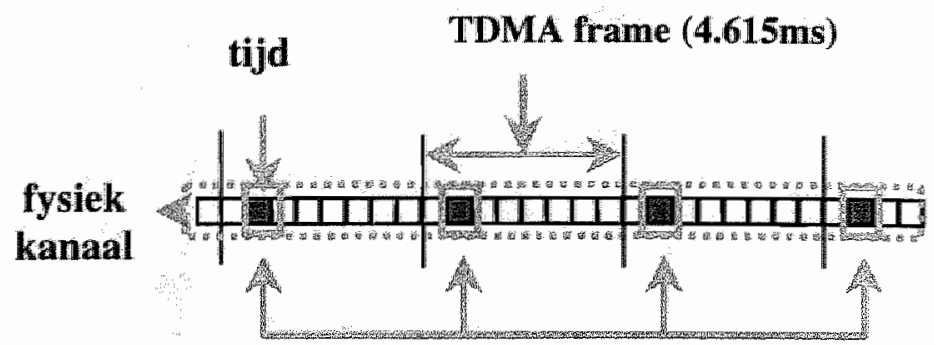

radío

Bron: Net werken met netwerken, KPN Research

Om draadloos signaaltransport te realiseren is een netwerk van antennes nodig. Het eerste probleem is om de antennes te positioneren, in groepjes van 2 tot 6 per cel, maximaal 3 cellen per site. Hiernaast staat een antenne afgebeeld, overigens samen met dezelfde monteur als eerder. De selectie van sites is tegenwoordig het grootste probleem. Men vindt een antenne op het dak van een huis een onprettig idee, en langs de wegen ondervindt met last van horizonvervuiling. Een creatieve oplossing voor het laatste probleem is langs de A2 in Hunsel (Limburg) uitgeprobeerd. Het heeft vooralsnog geen navolging ondervonden.

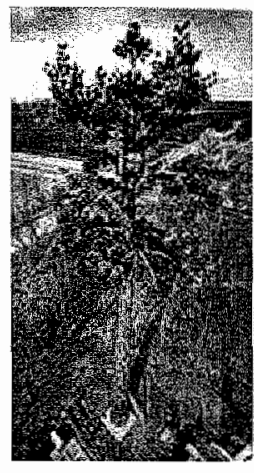

Na platsing van antennes is het tweede probleem frequenties toe te wijzen aan de antennes, die zo min mogelijk met frequenties van nabije buren interfereren. Hiertoe worden de frequenties genummerd van 1 tot $\mathrm{N}$ (rond de 50). De interferentie beperkingen luiden in vereenvoudigde vorm dat antennes van naburige sites niet dezelfde frequentie mogen hebben: de afstand op de frequentieband moet minstens 1 zijn. Antennes op dezelfde sitte moeten zelt's nog een band meer verschillen: de afstand moet minstens 2 zijn. Als we dit laatste niet zouden meenemen houden we een kleuringprobleem over:

Gegeven een graaf. Kleur de punten zodanig dat alle verbonden punten verschillende kleuren hebben. Indien de graaf planair is heeft dit probleem een aardige interpretatie: Gegeven een 2-dimensionaal oppervlak opgedeeid in een santal deelvlakken, met hoeveel kleuren kan ik dan toe. Appel en Haken [1,2] hebben aangetoond dat in dit geval 4 k]euren altija voldoende is. Het bewijs van deze stelling is binnen de wiskunde nogal 
onconventioneel. Met de computer zijn vele structuren geelimineerd. Dit niet erg praktische bewijs doet weinig recht aan de elegantie van de stelling. Recent is een nieuw veel korter maar nog steeds niet erg elegant bewijs van Robertson et alii [18] gepubliceerd.

Een goed onderzocht probleem binnen de literatuur over frequentie toewijzing is het zogenaamde minimum span probleem, waarbij de walarde van $\mathbb{N}$ zo klein mogelijk genomen moet worden. Hiervoor zijn diverse methoden bekend, die goede waarden voor $\mathrm{N}$ vinden. De kwaliteit van deze methoden is echter onduidelijk zolang we niet weten wat de beste waarde voor $\mathrm{N}$ is. Dit kunnen we doen door in de graaf van afstanden het kortste pad door alle punten te vinden, een minimum Hamilton pad.
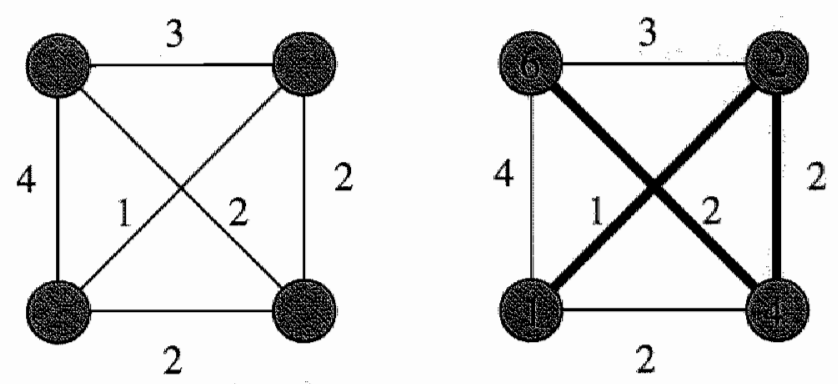

In Maastricht hebben we ons veelvuldig beziggehouden met Frequentie toewijzingsproblemen, waarbij kosten verbonden zijn aan het schenden van de interferentie beperkingen. Deze problemen zijn opgelost met behulp van polyhedrale technieken en dynamische programmering, waarbij intensief gebruik wordt gemaakt van de structuur van het netwerk van interferentie beperkingen. Zie Koster [11] en Koster et alii [12,13].

Het GSM netwerk heeft door het toegepaste protocol voor FDMA en TDMA een beperkte capaciteit van $8 \mathrm{~kb} / \mathrm{s}$ voor afzonderlijke gebruikers beschikbaar. Technieken met een hogere capaciteil zijn daarom in ontwikkeling. Op dit moment is dat GPRS en in de ( nabije toekomst UMTS. Deze laatste geeft de mogelijkheid om (gedeeld) tot $2 \mathrm{Mb} / \mathrm{s}$ informatie te verzenden en ontvangen op een $5 \mathrm{MHz}$ band.

\section{Nieuwe diensten (IP en ATM)}

De vraag naar capaciteit voor datatransport (bestanden, foto"s, geluid, video) heeft speciaal hiervoor geoutilleerde diensten met hun eigen protocol 
tot gevolg gehad. Er zijn er momenteel twee beschikbaar, namelijk IP (speciaal voor internet geschikt) en ATM (hoge kwaliteit) De diensten worden (naast gewone telefonie en mobiele telefonie op het vaste netwerk) als overlay netwerk, dus gescheiden, ingebed in het basis netwerk (het universele transmissie netwerk (UTN)). Dus iedere dienst krijgt zijn eigen bandbreedte toegewezen. Verder heeft ieder van deze diensten zijn eigen protocol. Beide protocollen zijn gebaseerd op packet-switching in plaats van circuit-switching, wat wil zeggen dat ze data splitsen in kleine pakketjes en deze dan in het netwerk versturen. De protocollen verschillen wel in de gehantearde packet-groottes, adressering en routering methoden. Hieronder volgt een overzicht van de planningsproblemen die bij beide protocollen naar voren komen.

Met de invoering van packet-switching heeft ook het begrip "bandbreedte" zijn intrede gedaan. De bandbreedte van een connectie is het aantal (M)b/s dat aan een verbinding toegekend wordt. Ze bepaalt dus de duur in tijd voor het overbrengen van een bestand. De bandbreedte hoeft overigens niet constant over de tijd te zijn.

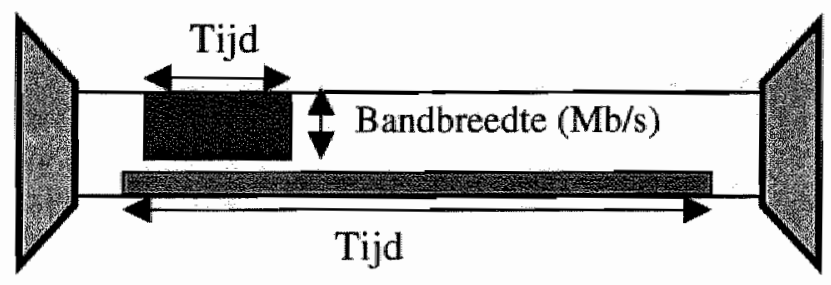

\section{Internet (TCP/IP protocol)}

Het internet is in feite een aansluiting naar een provider, die vervolgens het world-wide web toegankelijk maakt. De aansluiting naar de provider kan op verschillende manieren tot stand komen: het telefoonnetwerk, waarop smalbanddiensten (telefoon, ISDN) en breedbanddiensten (ADSL) gevoerd kunnen worden; de kabel; en in de toekomst hopelijk glasfiber.

Het protocol voor het Internet (en al haar diensten) heeft een aantal eigenaardigheden. Zo is de pakketgrootte wisselend, typisch tussen de 100 en 1000 bytes en hebben de klassieke planningsproblemen hun eigen variant voor het Internet.

1. Beschikbaarheid. Het verkeer bij IP is geen Poisson wachtrijproces meer, zoals bij telefonie. Er worden op erg willekeurige momenten 
aanvragen voor een willekeurig aantal files gedaan van zeer uiteenlopende grootte. Dit is een "bursty" proces. Dit proces heeft wel een prettige eigenschap die "self-similarity" genoemd wordt, wat zoveel wil zeggen als: op welke tijdschaal je ook kijkt het proces blijft even "bursty". De QoS eisen aan de capaciteit van een netwerk met deze eigenschap zijn echter een stuk moeilijker te realiseren als voor telefonie.

2. Routering. Voor iedere commodity (verkeer van een bepalald punt A naar een bepaald punt B) bestaat er één route in het netwerk waar alle verkeer van A naar B over plaatswindt. Deze route is het kortste pad van $A$ naar $B$, bij kantlengten die door de beheerder van het netwerk zelf ingesteld kunnen worden. De instellingen bepalen in grote mate het daadwerkelijke gebruik van de capaciteit. Als voorbeeld nemen we onderstaand netwerk, met vraag als gegeven in het linker plaatje. Op basis daarvan besluiten we capaciteit als in het rechter plaatje neer te leggen. Het advies van de apparatuurleverancier, CISCO, is nu om de kantlengten op de reciproke van de capaciteit, $1 / C$ in te stellen. Dit heeft tot gevolg dat het verkeer tussen de punten $c$ en d via a en b verloopt: $\frac{1}{3}+\frac{11}{4}+\frac{1}{3}<\frac{1}{1}$. Er treedt congestie op tussen a en b en de capaciteit tussen $c$ en $d$ blijft ongebruikt, een inefficiënte situatie. Dat lijkt dom wan CISCO, maar u moet zich wel realiseren dat CISCO leverancier van capaciteit is en geen gebruiker.
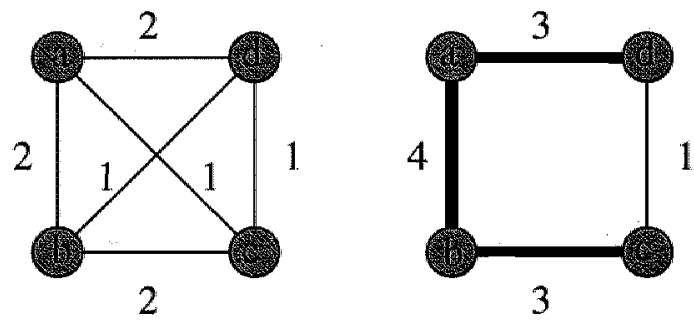

Fortz en Thorup [8] hebben cen methode ontwikkeld om, rekening houdend met de vraag effectiever lengtes te bepalen.

3. Capaciteitsreservering. Het TCP/IP protocol weigert nooit een aanvraag voor datatransport van a naar b. Op de kortste route wordt gekeken wat de vrij bandbreedte (in $\mathrm{kb} / \mathrm{s}$ ) is op ieder van de te gebruiken verbindingen. Van het minimum hiervan wordt een fractie toegekend aan de aanvraag. Dit zorgt ervoor dat het netwerk 
bij intensief gebruik soms erg traag wordt met hele lage download snelheden.

Bovenstaande eigenaardigheden van TCP/IP maken dit protocol ongeschikt voor datatransport met hoge kwaliteitseisen ten aanzien van snelheid en bandbreedte: Daarom is een ander type packet-switched protocoll, ATM, ontwikkeld. Dit protocol laat reservering van bandbreedte voor klanten toe. Daarnaast heeft ATM ook een snellere verwerking, dus minder vertraging door een constante (en kleinere) pakketgrootte. Deze bedraagt 53 bytes, 5 voor adressering en 48 voor informatie. De 48 voor informatie is inzet van veel discussie geweest: Amerikaanse technici wilden 32 en de Europeanen 64. De politicus die zich er toen mee bemoeide heeft met gevoel voor compromis besloten dat het 48 zou worden. Op de kritiek van beide groepen technici dat 48 geen macht van 2 was, reageerde de politicus met de vraag of dat werkelijk zo was.

De combinatie capaciteitsplanning en routering makt van ATM planning een bijzonder interessant onderzoeksonderwerp, zie Van de Leensel [15]. Als voorbeeld een klein netwerk van drie punten waarover tussen ieder paar 0,5 eenheden capaciteit beschikbaar moet zijn. In de oplossing van het tweede plaatje krijgt iedere verbinding een eenheid, en deze kost dus drie eenheden capaciteit. Als we echter én verkeersstroom, zeg die tussen 2 en 3 , via punt 1 routeren, zijin er nog slechts twee eenheden nodig.

Oplossing 1: kosten 3

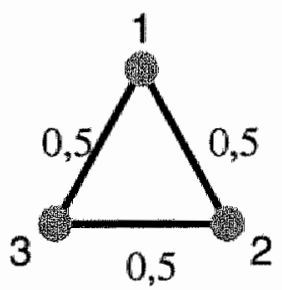

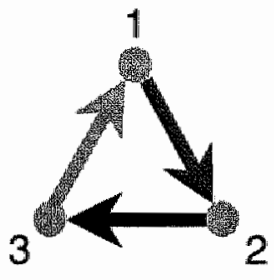

Oplossing 2: kosten 2

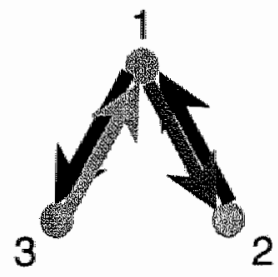

Voor de toekomst staat een vergaande integratie wan IP en ATM gepland, waarbij twee typen service kwaliteit zullen worden aangeboden, en het mogelijk wordt voor ieder van deze typen een bepaalde hoeveelheid bandbreedte af te nemen als klant. Op deze bandbreedte worden dan alle informatiestromen afgehandeld. 


\section{De informatie snelweg op dit moment.}

Wat ligt er nu op de versehillende niveaus in het netwerk, en waar liggen de bottlenecks? Hiertoe moeten we onderstaand plaatje bekijken, waar voor de verschillende netwerkniveaus de haalbare bandbreedte staan gegeven. Hieruit blijkt dat de bottleneck in het netwerk, zowel bij mobiel als vast verkeer bij het laagste niveau ligt: die naar de aansluiting. Voor vaste netwerken wordit dit opgelost in de toekomst met FTTH (Fiber to the Home). Voor mobiel verkeer worden nieuwe technieken zoals UMTS ingezet. Beide vergen grote investeringen, en zijn daardoor erg onzeker met betrekking tot het tijdpad waarbinnen ze gerealiseerd worden.

\section{Capaciteit op ieder niveau}

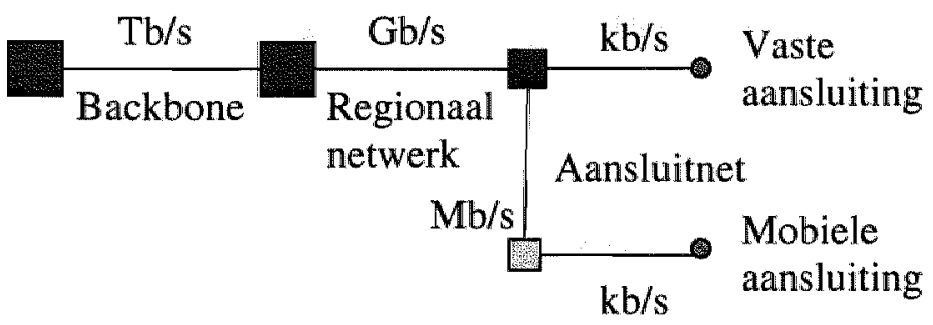

\section{Ontwikkelingen in de toekomst.}

In de nabije toekomst lijken twee ontwikkelingen door te zetten.

1. Kleine draadloze netwerken zoals "Bluetooth".

2. Competitie op nationale en internationale verbindingen. Tariefstructuren bepalen de hoeveelheid klanten.

\section{Draadloze lokale netwerken}

Draadloze lokale netwerken, LANs, met een capaciteit van $10-100 \mathrm{Mb} / \mathrm{s}$ zijn nu volop in ontwikkeling. Apparaten zoals desktops, laptops, maar ook huishoudelijke apparaten worden uitgerust met een zender/ontvanger. Deze zender/ontwangers maken onderdeel uit van een netwerk op (zeer) kleine schaal. De Bluetooth technologie is wel de meest bekende in zijn soort. Met name de software voor deze netwerken is nog volop in ontwikkeling om geoptimaliseerd te worden voor een dynamische omgeving. In deze omgeving willen we samenhang (liefst meervoudig) ter protectie tegen verbindingsverbreking. Deze netwerken zijn vergelijkbaar met "random" netwerken, waarvoor we de nodige theorie reeds ontwikkeld hebben. Zo 
gellt bijvoorbeeld voor een gegeven dichtheid van zenders dat de samenhang met grote waarschijnlijkheid gelijk is aan de (minimum) graad van de zenders in het netwerk.

\section{De telecompetitie}

Een laatste boeiende ontwikkeling binnen de telecom wereld is de introductie van concurrentie. Hierdoor kan een klant straks een verbinding tussen A en B op vele manieren kan verwezenlijken, gebruik maken wan de goedkoopste verbindingen.. Het is daarom aan de telecom operators am de tarieven van hun verbindingen zodlanig vast te stellen dat ze aan de ene kant zo goedkoop zijn dal een klant ze kiest, , en aan de andere kant zoveel mogelijk verdienen. In zijn algemeenheid is dit een dynamisch probleem waarin concurrenten voortdurend hun prijzen aanpassen aan de anderen, een speltheoretisch probileem. Het statische probleem waarbij de prijzen van de concurrenten als gegeven worden beschouwd is al een bijzonder complex probleem waarvan hieronder een voorbeeld. Zie Labbé et alii [14].

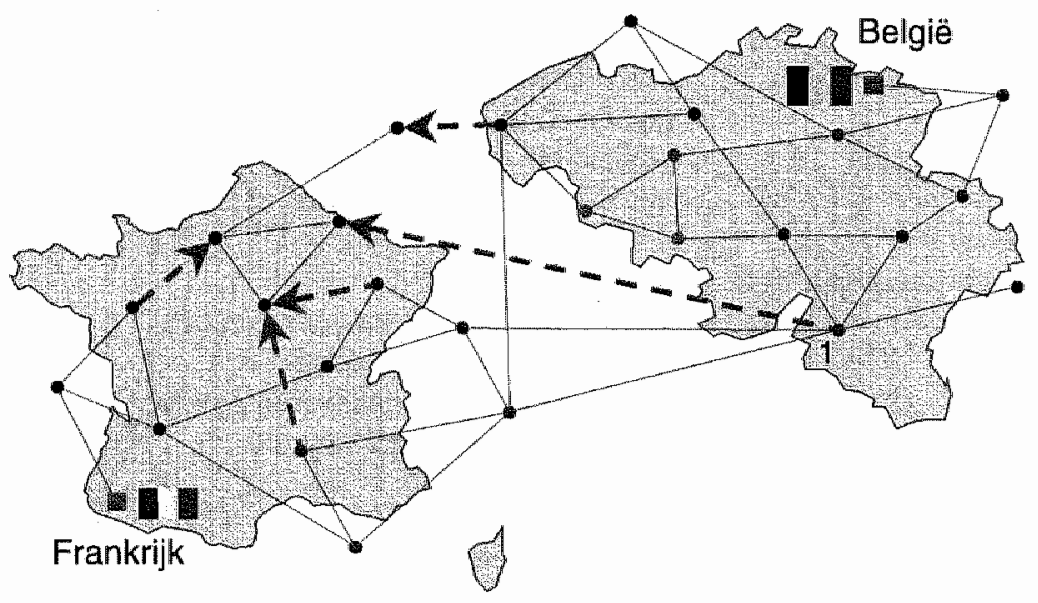


In bovenstaand plaatje zijn de verbindingen waar het tarief over bepaald moet worden gearceerd. Over de andere verbindingen is een vast tarief gegeven. Om nu "Toulouse" met "Turnhout" te verbinden kiest een klant een route met minimale kosten. De tarieven die de operator ontwangt over zijn gebruikte verbindingen vormen de opbrengsten, die deze wil maximaliseren. Merk op dat in het algemeen meerdere klanten hetzelfde probleem hebben.

\section{Toekomstvisie}

Een visie geeft je altijd de mogelijkheid om je te meten met de groten der aarde. Voordat ik mijn eigen ideeën geef, wil ik daarom eerst enkele profetieèn van beroemde professionals aan u voorleggen:

1. "Radio has no future", Kelvin, 1897

2. "There is a world market for maybe 5 computers", Watson (IBM), 1943.

3. "There is no reason anyone would want a computer in their home", Olsen (DEC), 1977.

4. "640K should be enough for anybody", Gates, 1981 .

5. "Er is geen gevaar dat de telecom bedrijven zullen overbieden op de UMTS veilingen, (CPB), 2000.

De onbekende van het CPB mag dan nog geen persoon van wereldfaam zijn, zijn uitspraak heeft alles in zich om door het nageslacht herinnerd te worden: hij is al snel volkomen achterhaald is. Hieronder volgen mijn eigen pogingen om toe te treden tot voornoemd gezelschap:

- UMTS is overbodig. Deze uitspraak lijkt een "open deur" gegeven de vertraging van de introductie, en wegens de "geringe" meerwaarde ten opzichte van reeds ingevoerde technieken zoals GPRS. Daarnaast zijn er nog weinig applicaties alleen geschikt voor UMTS. Ten slotte waren in sommige grote landen de licenties zo duur dat men zich af kan vragen waar telecom operators het geld voor investeringen in een UMTS netwerk vandaan halen. Echter de kans is groot dat woornoemde punten ook gaan gelden voor eventuele opvolgers van UMTS en dat haar bestaansrecht opgerekt kan worden tot enige jaren.

- Bandbreedte wordt spotgoedkoop. Dit lijkt door de overvloed aan concurrentie en de snelle technische ontwikkelingen wel 
bewaarheid te worden. Temeer als men bedenkt dat toepassingen, en dus de vraag naar bandbreedte, zich münder snel ontwikkelen.

- Kleinschalige draadloze dynamische netwerken hebben geen toekomst. Deze netwerken hebben geringe meerwaarde ten opzichte van de huidige producten. Net alls met de Chipper in vergelijking mel de pinpas en/of gewoon geld, is de meerwaarde te klein ten opzichte wan reeds bestaande middelen. De consument zal niet makkelijk in deze technologie investeren.

- Telecom operators ontwikkelen een vereenvoudigde netwerk structuur waarin zware backbones uitlopen naar iets lichtere vaste verbindingen. Bij de klant wordt voldoende draadloze bandbreedte geínstalleerd. Dit is mijn persoonlijke nachtmerrie scenario, omdat de planning dan een stuk cenvoudiger zou worden. Ik heb er echter het volste vertrouwen in dat de telecom operators dit niet snel zullen realiseren, onder andere omdat dit oude investeringen waardeloos zou maken.

Ik heb hier diverse uitspraken bij elkaar gezet om de kans te maximaliseren dat tenminste ển uitspraak van wereldkaliber is. Men heeft toch de neiging om de andere te vergeten.

\section{De "hype" is over}

Tot op heden hebben we de interessante technische en besliskundige ontwikkelingen aan ons voorbij zien trekken. Men vergeet soms dat deze ontwikkelingen van de telecom sector enorme investeringen vroegen en vragen. Kunnen deze bedrijven zulke investeringen nog wel opbrengen in de toekomst. Hiertoe hebben we de beurskoersen van drie willekeurige telecom bedrijven, allen actief in Nederland, genomen: KPN, UPC en Versatel.
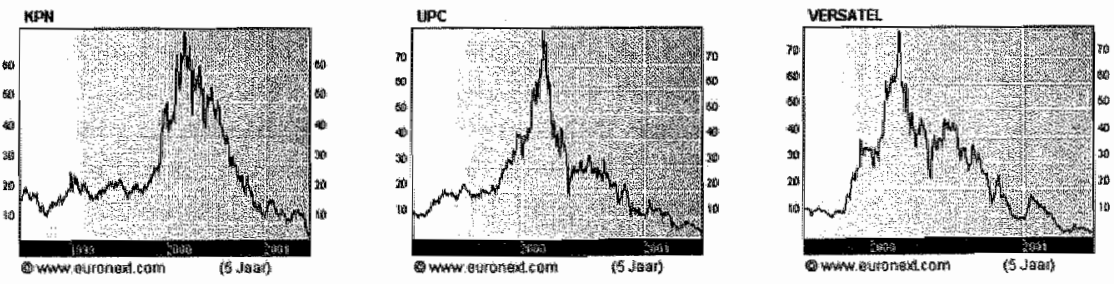

Bron: www.euronext.com

Zoals uit de grafieken volgt zijn deze koersen, niet geheel verrassend, sterk gecorreleerd. Als we deze koersontwikkeling zouden extrapoleren naar de 
toekont, komen we over twee maanden op negatieve koersen voor KPN: Dit lijkt technisch misschien niet zinvol, maar in een aandelenmarkt die overloopt van sentiment zullen sommige trotse bezitters van een aandeel KPN u wellicht geldelijk willen belonen voor de overname van hun stukken. Voor wie overigens geen twee maanden geduld heef: UPC en Versatel zitten binnen eén maand al in de min.

\section{Informatie logistiek}

We maken onderscheid tussen informatie logistiek (IL) binnen organisaties en tussen organisaties. In het laatste geval de externe IL, refereren we aan de telecom infrastructuur zoals hierboven beschreven. De interne IL houdt zich bezig met de informatiestromen binnen een bedrijf, zowel horizontaal als vertikaal. In beide gevallen handelt het zich om:

\section{"delivering the right information at the right time to the right place"}

Dit houdt in dat we ons richten op nieuwe applicaties die er voor kunnen zorgen dat informatie beter beschikbaar komt en beter gebruikt wordt. Producten, zoals SMS, WAP etc. zijn slechts het bescheiden begin. ERP software voor productie bedrijven en GPS software voor vervoersbedrijven zijn reeds ontwikkeld. Electronische verkoop en electronische markten zijn volop in ontwikkeling. Steeds meer zullen vergaand geïndividualiseerde vormen van informatie beschikbaar komen. Binnen de universiteit, per slot van rekening ook een organisatie, worden nieuwe methoden ontwikkeld om het product "kennis" meer op het individu toegespitst over te brengen. Collega's Gijselaars en Kirschner zullen beamen dat het goed voor deze universiteit is om ook hier een voortrekkersrol te vervullen. Ik hoop van ganser harte dat dit zal lukken. Ik verheug me in ieder geval enorm op een vruchtbare samenwerking met de diverse collega's van de aan $\mathrm{IL}$ gerelateerde vakgebieden binnen en buiten de FdEWB. 


\section{Dankwoord}

Als eerste wil ik het College van Bestuur en de Stichting Wetenschapsbeoefening bedanken voor deze voor mij zo bijzondere benoeming alsmede voor het in mij gestelde vertrouwen.

Tenslotte wil ik nog enkele mensen bedanken die een grote invloed op mijn wetenschappelijke leven en mijn privë leven hebben gehad.

Antoon Kolen will ik als eerste bedanken. Hij is een van de weinigen die gedurende mijn gehelle wetensichappelijke carrière een stimulerende factor is geweest. Hij heeft mijn eerste schreden op besliskundig onderzoek begeleid, en hij oefent nog steeds veel invloed uit op mijn onderzoek. Dit mag blijken uit de diverse publicaties die we samen op onze naam hebben staan. Albert Wagelmans heeft, vanuit mijn oogpunt, veel met Antoon gemeen: hij heeft met mij een vruchtbare AIO-periode doorgemaakt en ook daarna hebben we nog regelmatig samengewerkt.

Mijn ouders wil ik bedanken woor hun inzet voor mijn welzijn tot op de dag van vandaag. Ze hebben me altijd onvoorwaardelijk gesteund, en me de kans gegeven om in alle vrijheid mijn weg te vinden.

Als laatste wil ik Carin bedanken voor de 11 jaren die we nu bij elkaar zijn. Ik hoop met jou en Clint en ... nog vele jaren samen door te brengen.

\section{Ik heb gezegd.}




\section{Literatuur}

[1] Appel, K., Haken, W. Every planar map is four colorable, Part I. Discharging. Illinois J. Mathematics 21:429-490, 1977.

[2] Appel, K., Haken, W. Every planar map is four colorable, Part II. Reducibility. Ilinois J. Mathematics 21:491-567, 1977.

[3] Dell'Amico, M., Labbé, M. and Maffioli, F. Exact solution of the SONET ring loading problem. 96/05.

[4] Erlang, A.K. The Theory of Probabilities and Telephone Conversations, Nyt Tidsskrift for Matematik $B$ 20, 1909. Zie ook http:/plus.maths.org/issue2/erlang/, bezocht 25 juni 2001.

[5] Ford, Jr, L.R. and Fulkerson, D.R. Maximal flow through a network. Canadian Journal of Mathematics 8:399-404, 1956.

[6] Fortz, B. Design of Survivable Networks with Bounded Rings. Proefschrift, Université Libre Bruxelles, 1998.

[7] Fortz, B., Hoesel, C.P.M. van. Synthesis of tree networks. Unpublished manuscript.

[8] Fortz B., Thorup M. Internet Traffic Engineering by Optimizing OSPF Weights, unpublished manuscript, 2000.

[9] Gomory, R.E. and Hu, T.C. Multi-terminal network flows. SIAM J. Applied Mathematics 9:551-570, 1961.

[10] Huffman, D. A. A Method for the Construction of MinimumRedundancy Codes. Proc. IRE 40(9): 1098-1101, 1952. Zie ook: Beidler, Huffman Code - Part 1, http://www academic. uofs.edw/faculty /BEIDLER/cmps 144/huffman.html, bezocht 25 juni 2001.

[11] Koster, A.M.C.A. Frequency assignment: models and algorithms. Proefschrift, Universiteit Maastricht, 1999.

[12] Koster, A.M.C.A., Hoesel, C.P.M. van, Kolen A.W.J. The Partial Constraint Satisfaction Problem: Facets and Lifting Theorems. Operations Research Letters 23 (3-5): 89-97, 1998.

[13] Koster, A.M.C.A., Hoesel, C.P.M. van, Kolen A.W.J. Solving Frequency Assignment Problems via Tree-Decomposition, Electronic Notes in Discrete Mathemarics, 3, 1999. Proceedings of TW6.

[14] Labber, M., Marcotte, P. and Savard, G. A bilevel model of taxation and its application to optimal highway pricing. Management Science 44(12): 1608-1622, 1998.

[15] Leensel, R.L.M.J. Models and algorithms for telecommunication network design. Proefschrift, Universiteit Maastricht, 1999.

[16] Menger, K. Zur allgemeinen Kurventheorie. Fundamenta Mathematicae 10:96-115, 1927

[17] Okamura, H., Seymour, P. Multicommodity flows in planar graphs. $J$. Combinatorial. Theory. B 31:75-81, 1981. 
[18] Robertson, N., Sanders, P., Seymour, P., Thomas, R. A new proof of the four-colour theorem. Electronic research announcements of the American mathematical society 2(1):1-9, 1996.

[19] Schrijver, A. On the history of the transportation and maximum flow problems. (to appear in Mathematical Programming)

[20] Schrijver, A., Seymour, P., Winkler, P. The ring loading problem. SIAM J. Discrete Mathematics. 11(1):1-14, 1998.

[21] Tolstoil, A.N. Methods of finding the minimal total kilometrage in cargo-transportation planning in space (in Russian). In: Planirovanie Perevozok, Sbornik pervyä, Transpechat' NKPS, Moscow, 23-55, 1930.

[22] Wessäly, R. Dimensioning Survivable Capacitated NETworks. Proefschrift, ZIB Berlin, 2000.

[23] Wu, B.-Y., Lancia, G., Bafna, V. Chao, K.-M., Ravi, R., Tang, C.Y. A polynomial-time approximation scheme for minimum routing cost spanning trees. SIAM J. Computing 29(3):761-778, 1999.

[24] Wynants, C. Network Synthesis Problems. Proefschrift, Université Libre Bruxelles, 1999. 